\title{
PENGARUH IMPLEMENTASI PEMBELAJARAN BERBASIS AFEKSI BERBANTUAN MEDIA POSTER TERHADAP KEPEKAAN SOSIAL DAN HASIL BELAJAR IPS PADA SISWA KELAS IV SD INPRES SIKUMANA 3 KOTA KUPANG
}

\section{OLEH:}

\section{MUHAMAD RUSADI LETASADO ${ }^{1}$, JULHIDAYAT MUHSAM ${ }^{2}$ (PGSD UNIVERSITAS MUHAMMADIYAH KUPANG ${ }^{1,2}$ )}

\begin{abstract}
The aimed of this study is to determine the effect of the implementation of affection-based learning by using poster media on students social sensitivity and social studies learning outcomes at fourth grade students of SD Inpres Sikumana $3^{\text {rd }}$, Kupang City. This study used a quasi-experimental method by using the Single Factor Independent Group Design. The population of this study was 70 students. 35 students were selected as samples, which is drawn by random sampling technique, and the data collection of this study used the objective test method.The data were analyzed using multivariate analysis of variance (MANOVA). The results of this study indicated that: (1) there was an effect of the implementation of affection-based learning by using poster media on students' social sensitivity. (2) there was an effect of the implementation of affection-based learning by using poster media on students' social studies learning outcomes. (3) there was an effect of the implementation of affection-based learning by using poster media simultaneously on students social sensitivity and social studies learning outcomes.
\end{abstract}

KeyWords: social studies, social sensitivity, poster media, affection-based learning

\section{PENDAHULUAN}

\section{Latar Belakang Masalah}

Pendidikan menuntut banyak sekali perbaikan dan perubahan dimana pergantian kurikulum meyebabkan perubahan dalam perangkat dan pola mengajar guru. Hal ni terlihat pada pergantian rancangan pembelajaran dari KTSP ke Kurikulum 2013, kurikulum 2013 menuntut adanya inovasi dalam belajar. Dantes ( 2017) mengemukakan bukan hanya siswa yang menjadi pusat pembelajaran tapi 
guru menjadi pusat pembelajaran dimana guru sekarang bertugas menjadi fasilitator dandiharapkan agar mampu kreatif, inovatif melaksanakan proses belajar yang seimbang dengan harapan kurikulum 2013 saat ini.Kegiatan manusia yang kompleks merupakan wujud dari sebuah pembelajaran, namun tidak sepenuhnya mampu diartikan. Kegiatan interaksi menggunakan berbagai metode dan strategi antara pendidik dan siswa agar siswa mampu untuk melaksanakan kegiatan belajar merupakan makna dari sebuah pembelajaran (Muh dan Uslan, 2020)

Diterangkan lagi, interaksi yang terjadi antara guru dan peserta didik merupakan wujud dari pembelajaran yang diharapkan mampu menaikan minat belajar peserta didik.Pengembangan maupun pengalaman hidup mampu di jabarkan secara simple sebagai produk interaksi berkelanjutan dari sebuah pembelajaran (Lamahala dkk., 2018). Pembelajaran yang bermakna merupakan hal yang dibutuhkan setiap siswa sehingga apa yang diajarkan mampu di pahami siswa. Rangkaian kegiatan mampu di defenisikan sebagai perencanaan yang berisi tentang desain strategi pembelajaran yang tercantum kegiatan sehingga tercapai tujuan yang diharapkan (Hasyda \& Djenawa, 2020). Melalui pembelajaran IPS disekolah dengan menggunakan strategi yang tepat diharapkan mampu memberikan bekal kepada siswa dalam menempuh jenjang pendidikan selanjutnya. Tetapi pembelajaran di kelas tidak sesuai dengan yang direncanakan karena masih ditemui permasalahan dalam proses pembelajaran. Siswa cenderung duduk, diam tanpa memberikan stimulus terhadap materi ajar selama proses pembelajaran berlangsung, sumber belajar tunggal bagi siswa adalah guru selain itu guru yang memiliki kompetensi hanya sedikit yang sesuai dengan bidangnya 
(Letasado dan Muhsam, 2020).

Kepribadian manusia berdampak positif maupun negatife tergantung pada penguasaan manusia terhadap materi, inilah yang menjadi alasan pentingnya pendidikan afeksi di sekolah agar manusia mampu bertanggung jawab dalam kehidupan.Dalam mewujudkan jati diri kemanusiaan, upaya menyadarkan individu yang paling ampuh adalah dengan pendidikan,kehalusan budi, jiwa, kecemerlangan pikir, kecekatan raga, dan memiliki kesadaran penciptaan dirinya mampu dihasilkan lewat pendidikan, kualitas pendidikan berdampak dua atau tiga kali lebih kuat dalam membentuk manusia dibanding faktor lain (Aiman \& Ahmad, 2020).

Untuk memberikan pembelajaran IPS yang bermanfaat, perlu menghasilkan media pembelajaran yang sesuai dalam pembelajaran IPS dan harus di imbangi dengan pembelajaran yang bermakna.Media poster merupakan salah satu alternatif dalam menciptakan pembelajaran yang kreatif, penyampaian penggambaran sebagai peringatan, pemberitahuan, perintah, maupun penyampaian selera yang disampaiakan secara visual. Melalui observasi yang telah terlaksana, diketahui bahwa materi yang diterapkan oleh pendidik SD Inpres sikumana 3 kelas IV kota kupang didominasi cara-cara tradisional, pembelajaran dirasakan masih melibatkan metode satu arah akhirnya menyebabkan siswa menjadi pasif di dalam kelas. Dalam mengatasi masalah pembelajaran ini peneliti mengembangkan pembelajaran berbasis afeksi berbantuan media poster, sehingga peserta didik memiliki kemampuan afektif, kognitif, dan konatif yang seimbang. Keunggulan dari pembelajaran berbasis afeksi adalah siswa mampu Merasakan keseimbangan antara sikap yang diperoleh, memiliki jiwa sosial tinggi, mampu 
memecahkan masalah, kreatif, saling membantu antar sesama dan mampu memaksimalkan kecerdasannya.Sehingga perlu untuk diterapkan agar lebih semangat, menarik, memberikan kesan visual sebagai gambaran komprehensif materi, lebih efisiensi dan efektif.

\section{METODE PENELITIAN}

Penelitian dilaksanakan di SD Inpres Sikumana 3 Kota Kupang dengan rentang waktu dari bulan februari sampai dengan april tahun 2020. Jumlah Populasi semua peserta didik kelas IV SD Inpres Sikumana 3 kota kupang. Menggunakan teknik (random sampling) sebanyak 2 kelas.Dimana kelas IVA dijadikan kelas eksperimen dengan jumlah peserta didik 35 orang dan kelas IVB sebagai kelas kontrol sejumlah 35 orang. Tiga variable digunakan. Pembelajaran afeksi sebagai variable bebas sedangkan variable terikat kepekaan sosial dan hasil belajar IPS.

Penelitian Eksperimen semu (quasi eksperimen) dalam siswa suatu kelas. Dengan rancangan penelitian Single Factor Independent Group Design.yang ditunjukkan pada tabel 01 .

Tabel 01. Rancangan Penelitian

\begin{tabular}{l|c|c|c}
\hline \multicolumn{2}{c|}{ E } & \multicolumn{2}{c}{ K } \\
\hline$Y_{1}$ & $Y_{2}$ & $Y_{1}$ & $Y_{2}$ \\
\hline
\end{tabular}

Single Factor Independent Group Design Dantes (2017)

Keterangan :

$\mathrm{E}=$ Kelas eksperimen

$\mathrm{K}=$ Kelas kontrol 
$Y_{1}=$ Kepekaan sosial

$Y_{2}=$ Hasil belajar IPS

Produser pada penelitian ada tiga tahap, yaitu: 1) tahap awal eksperimen, 2) tahap tindakan eksperimen, 3) tahap akhir eksperimen ketiga tahap tersebut adalah sebagai berikut:

1. Pada tahap awal eksperimen:, dilakukan persiapan diantaranya survey awal ke sekolah, mempersiapkan alat-alat eksperimen, diantaranya media poster, sintaks pembelajaran dan skenario pembelajaran.

2. Pelaksanaan eksperimen: tahap ini pelaksanan pembelajaran menggunakan skenario yang telah disiapkan yakni pembelajaran afeksi berbantuan media poster kelas eksperimen dan kelas konvensional mengikuti pembelajaran dari guru.

3. Tahap akhir: melakukan evaluasi untuk mengetahui apakah terdapat pengaruh penggunaan pembelajaran berbasis afeksi berbantuan media poster terhadap kepekaan sosial dan hasil belajar IPS peserta didik.

\section{HASIL PENELITIAN DAN PEMBAHASAN}

\section{HASIL}

Rekapitulasi hasil analisis deskriptif data kepekaan sosial dan hasil belajar IPS peserta didik secara keseluruhan ditampilkan pada tabel dibawah ini. 
Tabel 02.Gambaran Hasil Analisis data kepekaan sosial dan hasil belajar IPS siswa

\begin{tabular}{l|c|c|c|c}
\hline & AIY1 & A1Y2 & A2Y1 & A2Y2 \\
\hline \multicolumn{1}{c|}{$\mathrm{N}$} & 35 & 35 & 35 & 35 \\
\hline Rerata & 72,73 & 74,00 & 62,17 & 62,14 \\
\hline Median & 74,00 & 75,00 & 61,00 & 60,00 \\
\hline Varians & 49,70 & 79,12 & 88,05 & 110,71 \\
\hline Std. Deviasi & 7,05 & 8,89 & 9.38 & 10,52 \\
\hline Nilai Minimum & 57,71 & 55,00 & 50,50 & 40,00 \\
\hline Nilai Maximum & 85,00 & 90,00 & 85,00 & 85,00 \\
\hline Rentangan & 27,29 & 35,00 & 34,50 & 45,00 \\
\hline Total & $\mathbf{2 5 4 5 , 7 1}$ & $\mathbf{2 5 9 0 , 0 0}$ & $\mathbf{2 1 7 6 , 0 5}$ & $\mathbf{2 1 7 5 , 0 0}$ \\
\hline
\end{tabular}

Keterangan :

A1Y1 = Kepekaan Sosial siswa kelompok eksperimen

A1Y2 = Hasil Belajar IPS siswa kelompok eksperimen

A2Y1 = Kepekaan Sosial siswa kelompok kontrol

A2Y2 = Hasil Belajar IPS siswa kelompok control

Pada penelitian ini diajukan 3 hipotesis. Hipotesis diuji dengan metode statistic menggunakan ANAVA A dan MANOVA. Dimana hipotesis 1 dan 2 diuji dengan formula ANAVA A dan 3 diuji MANOVA 
1. Rangkuman hasil Hipotesis 1 ditampilkan pada Tabel 03

\begin{tabular}{l|c|c|c|c|c|c|c}
\hline $\begin{array}{l}\text { Sumber } \\
\text { Varians }\end{array}$ & JK & Dk & RJK & F $_{\text {hitung }}$ & Sig & P & Ket \\
\hline Antar & 1955,714 & 1 & 1955,714 & 28,001 & & & Signifikan \\
Kelompok & & & & & 0,001 & 0,05 & \\
\hline Dalam & 4749,371 & 68 & 69,844 & & & & \\
Kelompok & & & & & & & \\
\hline Total & 6705,086 & 69 & & & & & \\
\hline
\end{tabular}

Tabel 03. Menunjukkan hasil $F_{\text {hitung }}=28,001$ dan sig $=0,001$. Ini berarti sig $\mathrm{p}<0,05$. Maka hipotesis nol tidak adanya pengaruh kepekaan social peserta didik pada pembelajaran berbasis afeksi dengan konvesional, "tolak". Hal ini mengartikan adanya efek kepekaan social peserta didik pada pembelajaran berbasis afeksi dengan pembelajaran konvensional.

2. Ringkasan hasil Hipotesis 2 disajikan Tabel 04

\begin{tabular}{|c|c|c|c|c|c|c|c|}
\hline $\begin{array}{l}\text { Sumber } \\
\text { Varians }\end{array}$ & JK & Dk & RJK & $\mathbf{F}_{\text {hitung }}$ & Sig & $\mathbf{P}$ & Ket \\
\hline $\begin{array}{l}\text { Antar } \\
\text { Kelompok }\end{array}$ & 2460,357 & 1 & 2460,357 & 25,921 & $<0,001$ & $<0,05$ & Signifikan \\
\hline $\begin{array}{l}\text { Dalam } \\
\text { Kelompok }\end{array}$ & 6454,286 & 68 & 94,916 & & & & \\
\hline Total & 8914,643 & 69 & & & & & \\
\hline
\end{tabular}

Berdasarkan Tabel 04, maka nilai $F_{\text {hitung }}=25,921$ dan sig $=0,001$. Sig $p<$ 
0,05. Diartikan bahwa hipotesis nol tidak berpengaruh hasil belajar IPS peserta didik pada pembelajaran berbasis afeksi dan konvensional, “ditolak". Maka simpulkan adanya berpengaruh hasil belajar IPS peserta didik melaksanakan pembelajaran berbasis afeksi dan konvensional.

\section{Ringkasan hasil hipotesis 3 ditampilkan Tabel 05}

\begin{tabular}{|c|c|c|c|c|c|c|}
\hline Efek & & Nilai & $\mathbf{F}$ & $\begin{array}{c}\text { df } \\
\text { hipotesis }\end{array}$ & $\begin{array}{c}\text { Df } \\
\text { kesalahan }\end{array}$ & sig. \\
\hline Intersep & $\begin{array}{l}\text { Trace } \\
\text { Pillai } \\
\text { Lambd } \\
\text { a Wilks } \\
\text { Trace } \\
\text { Hotelli } \\
\text { ng } \\
\text { Roy's } \\
\text { Largest } \\
\text { Root } \\
\end{array}$ & $\begin{array}{r}0,989 \\
0,011 \\
86,524 \\
86,524\end{array}$ & $\begin{array}{l}2,899 \\
2,899 \\
2,899 \\
2,899\end{array}$ & $\begin{array}{l}2,000 \\
2,000 \\
2,000 \\
2,000\end{array}$ & $\begin{array}{l}67,000 \\
67,000 \\
67,000 \\
67,000\end{array}$ & $\begin{array}{l}<0,001 \\
<0,001 \\
<0,001 \\
<0,001\end{array}$ \\
\hline Kelompok & $\begin{array}{l}\text { Trace } \\
\text { Pillai } \\
\text { Lambd } \\
\text { a Wilks } \\
\text { Trace } \\
\text { Hotelli } \\
\text { ng } \\
\text { Akar } \\
\text { Terbesa } \\
\text { rRoy }\end{array}$ & $\begin{array}{l}0,369 \\
0,631 \\
0,585 \\
0,585\end{array}$ & $\begin{array}{l}19,610 \\
19,610 \\
19,610 \\
19,610\end{array}$ & $\begin{array}{l}2,000 \\
2,000 \\
2,000 \\
2,000\end{array}$ & $\begin{array}{l}67,000 \\
67,000 \\
67,000 \\
67,000\end{array}$ & $\begin{array}{l}<0,001 \\
<0,001 \\
<0,001 \\
<0,001\end{array}$ \\
\hline
\end{tabular}

Tabel 05. Menampilkan hasil signifikansi uji Manova Pillai trace, Wilks' Lambda Hotelling's trace, dan Roy's largest Root sebesar 0,001 dan < 0,05. Disimpulkan bahwa tidak adanya berpengaruh secara simultan kepekaan social dan hasil belajar peserta didik di antara pembelajaran berbasis afeksi dan konvesional, “ditolak" dan hipotesis alternatif "diterima". Maka ditemui secara simultan kepekaan social dan hasil belajar IPS peserta didik diantara pembelajaran 
berbasis afeksi dan konvesional.

\section{PEMBAHASAN}

Pengujian hipotesis membuktikan bahwa pembelajaran berbasis afeksi berbantuan media poster mencapai hasil yang lebih tinggi dibandingkan dengan pembelajaran konvesional. Hasil analisis hipotesis 1 ANAVA A memperoleh nilai $\mathrm{F}$ sebesar 28,001 $\mathrm{Dk}=1 \mathrm{dan} \mathrm{Sig}=0,00$. Dapat dilihat skor Mean kepekaan social pada kelas eksperimen sebanyak 72,73 cenderung lebih tinggi dari rata-rata skor kelas kontrol 62,17. Diartikan belum mencapai KKM pada kelas kontrol.

Selanjutnya hasil hipotesis 2 mendapatkan nilai $\mathrm{F}$ sebesar 25,921 Dk $=1$ dan Sig $=0,001$. Jika melihat dari rata-rata skor hasil belajar IPS kelas eksperimen sebesar 74,00 kategori lebih tinggi dari rata-rata skor kelas kontrol 62,14. Artinya belum mencapai KKM pada kontrol.

Hipotesis 3 menunjukkan nilai $\mathrm{F}$ hitung 2,899 dengan kategori signifikan 0,001 pada Pillai's Trace, Wilks' Lambda, Hotelling's Trace dan Roy's Largest Root dari implementasi pembelajaran berbasis afeksi $<0,05$. Dengan melihat hasil skor rata-rata kepekaan social dan hasil belajar IPS peserta didik kelas eksperimen sebesar72,73 dan 74,00. Sedangkan kepekaan social dan hasil belajar IPS kelas kontrol sebesar 62,17 dan 62,14. Maka disimpulkan adanya berpengaruh implementasi pembelajaran berbasis afeksi berbantuan media poster secara simultan dengan kepekaan sosial dan hasil belajar IPS pada siswa kelas IV.

Hal ini didukung oleh penelitian sebelumnya yang dilaksanakan oleh (Aiman dkk., 2019) bahwa penelitian eksperimental semu dengan menggunakan SPSS 17.00 dalam menganalisis data. Berdasarkan hasil pretest maupun posttest di kelas eksperimen menggunakan model pembelajaran inkuiri terbimbing jauh 
lebih efektif untuk meningkatkan kepekaan sosial siswa ketimbang kelas kontrol yang melakukan model pembelajaran inkuiri murni. Analisis dengan uji t melakukan uji sampel independen, didapatkan t hitung sebesar 3,99 dengan taraf signifikansi 0,00 (sig <0,05), ini berarti Ho menolak dan menerima Ha. Penelitian ini membuktikan bahwa jika Ha diterima yang berisi penerapan model pembelajaran inkuiri terbimbing dalam pembelajaran IPS lebih bagus daripada penggunaan model inkuiri murni dalam meningkatkan kepekaan sosial siswa. Lebih lanjut Muhsam (2020) mengemukakan inkuiri layak digunakan sebagai metode pembelajaran yang dapat merangsang peserta didik untuk aktif dalam belajar.

\section{KESIMPULAN}

Dari hasil pengujian hipotesis dan pembahasaan, maka disimpulkan bahwa (1) terdapat pengaruh implementasi pembelajaran berbasis afeksi berbantuan media poster terhadap kepekaan sosial siswa. (2) terdapat pengaruh implementasi pembelajaran berbasis afeksi berbantuan media poster dengan hasil belajar IPS siswa. (3) terdapat pengaruh implementasi pembelajaran berbasis afeksi berbantuan media poster secara simultan terhadap kepekaan sosial dan hasil belajar IPS siswa.

\section{DAFTAR PUSTAKA}

Aiman, U., \& Ahmad, R. A. R. (2020). Model Pembelajaran Berbasis Masalah (PBL) Terhadap Literasi Sains Siswa Kelas V Sekolah Dasar. Jurnal Pendidikan Dasar Flobamorata, 1(1), 1-5.

Aiman, U., Dantes, N., \& Suma, K. (2019). Pengaruh model pembelajaran 
berbasis masalah terhadap literasi sains dan berpikir kritis siswa sekolah dasar. Jurnal Ilmiah Pendidikan Citra Bakti, 6(2), 196-209.

Dantes, N. (2017). Desain Eksperimen dan Analisis Data. Depok: Rajawali Pers. Hasyda, S., \& Djenawa, A. (2020). Penerapan Pembelajaran Kooperatif Picture and Picture Bermedia Mind Map untuk Meningkatkan Kemampuan Literasi Sosoal Pada Peserta Didik Sekolah Dasar. Jurnal Basicedu, 4(3), 696-706.

Lamahala, M. H., Lamen, S., \& Uslan, U. (2018). Pengembangan Media Jaringan Epidermis Tanaman Jagung (Zea Mays L.) Yang Tumbuh Di Kota Kupang Sebagai Sumber Belajar Tambahan Pembelajaran IPA SD Berbasis Kearifan Lokal. Jurnal Ilmiah Pendidikan Citra Bakti, 5(2), 15-25.

Letasado, M. R., \& Muhsam, J. (2020). Pengaruh Implementasi Pembelajaran Saintifik Berbasis Keterampilan Belajar dan Berinovasi 4C terhadap Percaya Diri dan Kemampuan Membaca Pemahaman. Musamus Journal of Primary Education, 76-84.

Muh, A. S., \& Uslan, U. (2020). Evaluasi Program Pendidikan Inklusi di Sekolah Dasar Abdi Kasih Bangsa. Musamus Journal of Primary Education, 102112.

Muhsam, J. (2020). Pengembangan Lembar Kerja Siswa (LKS) Berbasis Model Inkuiri Terintegrasi Life Skills Pada Siswa Kelas IV SD Negeri Oeba 3 Kupang. Jurnal Pendidikan Dasar Flobamorata, 1(1), 24-31. 